\title{
Distribution of endogenous albumin in the glomerular wall of streptozotocin-induced diabetic rats as revealed by high-resolution immunocytochemistry
}

\author{
M. Bendayan, D. Gingras and P.Charest* \\ Department of Anatomy, Faculty of Medicine, University of Montreal, Montreal, Quebec, Canada
}

\begin{abstract}
Endogenous albumin was revealed with high resolution in the glomerular wall of renal tissue from normoglycaemic and long-term streptozotocin-induced hyperglycaemic rats applying the protein A-gold immunocytochemical approach. In tissues from normal animals, albumin antigenic sites were detected at the level of the endothelial cell basal plasma membrane and in the subendothelial side of the lamina densa of the glomerular basal laminae. The epithelial side of the laminae was weakly labelled, while the urinary space was devoid of labelling. In the podocytes, labelling for albumin was confined to few lysosomal structures. In diabetic animals, concomitant with hyperglycaemy, low insulin levels, significant glycosuria, proteinuria and albuminuria, the glomerular basal laminae displayed the characteristic increase in thickness found in diabetic microangiopathy $(404 \pm 45 \mathrm{~nm}$ versus $190 \pm 10 \mathrm{~nm}$ ). Major basal laminae deposits were also found in the mesangial regions. Albumin antigenic sites were detected throughout the entire thickness of the glomerular basal laminae without any preferential accumulation at any
\end{abstract}

particular site. Labelling was also found over flocculent material present in the urinary space. Numerous densely labelled lysosomal structures were present in the podocytes. The basal laminae deposits in the mesangial regions were labelled for albumin. Morphometrical evaluations made on the distribution of the labelling confirmed the qualitative observations. Two sites for albumin retention were revealed in the glomerular wall of the normal animal: the endothelial cell basal membrane $(<10 \mathrm{~nm})$ and the subendothelial side of the lamina densa $(50 \mathrm{~nm})$. Besides the endothelial cell basal membrane $(<10 \mathrm{~nm})$ for the diabetic animals, no other site of retention was detected; the distribution of albumin was uniform throughout the basal laminae. These results are in agreement with the physiological demonstration of restricted passage of albumin through the glomerular wall in the normal condition and its loss in diabetes.

Key words: Diabetes, glomerulus, albumin, permeability, immunocytochemistry, protein A-gold.
The filtration unit of the glomerular wall is composed of three different and successive layers: an endothelium of the fenestrated type, a basal laminae and an epithelium composed of podocytes with foot processes anchored to the basal laminae and joined one to the other by thin slit diaphragms. A defined function has been attributed to each of these components: (a) the basal laminae as the main filter; (b) the endothelium as a valve; and (c) the epithelium as the monitor, recovering the proteins that leaked through the filter [1]. In addition to this filtration unit, a mesangium composed of mesangial cells and basal laminae deposits, present in between the glomerular loops, serves to recondition and unclog the filter by incorporating and disposing of filtration residues [1]. The integrity of all these elements is essential for the maintenance of the normal filtration properties of the unit. Physiological studies have demonstrated that, under normal conditions, the glomerular wall behaves like a sieve; it allows passage to small molecules, but restricts almost completely that of larger ones such as al-

* Present address: Department of Phytology, Université Laval, Quebec, Canada bumin $[2,3]$. In renal diseases, however, proteinuria is a common phenomena which appears to be concomitant to morphological alterations of the glomerular wall. In diabetic conditions in particular, functional and morphological modifications of the glomerular wall have been well documented [4-12]. However, correlations between the different alterations and the hyperglycaemic condition are still a matter of controversy.

In the present study we have investigated, through a morphoimmunocytochemical approach, the passage of serum albumin through the glomerular wall in control and long-term diabetic conditions. The high resolution protein A-gold immunocytochemical technique [13] adapted for the study of vascular permeability [14] was applied. The immunocytochemical approach as applied to the study of the vascular permeability of endogenous proteins presents significant advantages, since it is free of problems due to injection or infusion of non-physiological tracers [15-17]. The detection of rat albumin normally present in serum and tissues was performed on a post-embedding step, the albumin molecules being retained in their normal location by the fixation procedure. The study was focused on the glomerular wall of 
normal animals and of animals maintained hyperglycaemic for long periods of time demonstrating significant proteinuria concomitant with morphological alterations of the glomerular basal laminae.

\section{Materials and methods}

An experimental hyperglycaemic state was induced in $100 \mathrm{~g}$ SpragueDawley albino rats by intravenous injection of streptozotocin $(50 \mathrm{mg} /$ $\mathrm{kg}$ body weight, dissolved in $10 \mathrm{mmol} / 1$ sodium citrate, $\mathrm{pH} 4.5$ ). Eight animals maintained hyperglycaemic for 7 to 15 months were studied. Five animals injected with the same volume of sodium citrate were used as the control group. None of the animals were insulin-treated. Urine samples were collected and analyzed weekly using reagent strips (N-Multiplex, Ames, Ontario, Canada) for the presence of glucose, proteins and ketone bodies, as well as for $\mathrm{pH}$. The streptozotocin-injected animals exhibited glycosuria $24 \mathrm{~h}$ after the injection. The urinary glucose remained positive throughout the experiment. These animals also showed strong ketonuria and proteinuria with the urine $\mathrm{pH} \simeq 5$. Twenty-four hour urine volumes were collected on the last week of the experiment, before killing. Total proteins and albumin concentrations were analyzed. Total proteins were determined after precipitation with phosphotungstic acid, while albumin was measured by electrophoresis on agarose gel. The animals were killed by decapitation after a blow on the head. Blood samples were taken at that moment and analyzed for plasma glucose and insulin levels using the glucose oxidase method and the radioimmunoassay (insulin RIA Kit, Chromacod, BIORIA, Montreal, Canada) respectively. The pancreatic tissue of the different animals was fixed by immersion in Bouin's fluid and embedded in paraffin. Five $\mu \mathrm{m}$ thick sections were stained by the indirect immunofluorescent technique to reveal insulin containing cells in the islets of Langerhans, using an anti-insulin antibody and an anti-guinea pig IgG antibody labelled with fluorescein (both from Miles Laboratory, Elkhart, Ind, USA).

For the study of the renal tissue at the electron microscope level, small fragments of the renal cortex were fixed by immersion in $0.1 \mathrm{~mol} / 1$ phosphate buffer ( $\mathrm{pH} 7.4$ ) containing freshly prepared $4 \%$ formaldehyde for $2 \mathrm{~h}$ at $4^{\circ} \mathrm{C}$. They were then embedded in Lowicryl K4M (Chemische Werke Lowi GmbH, Waldkraiburg, FRG) at $-20^{\circ} \mathrm{C}$ according to the protocol described previously $[13,18]$.

For measurement of the glomerular basal laminae thickness, we applied the orthogonal intercept method [19] on micrographs enlarged to a final magnification of X 40000 . The distance between the endothelial cell and the podocyte was evaluated using a ruler on which the length was classified according to a log-reciprocal scale as performed previously [18-20]. A minimum of 200 measurements were made for each animal. The analysis was done using a modular system for quantitative digital image analysis (MOP-3, Carl Zeiss Inc, Montreal, Canada).

For the ultrastructural localization of endogenous rat albumin in the glomerular wall, the protein A-gold immunocytochemical technique [13] was applied with a specific rat albumin antibody (IgG fraction; Cooper Biomed Inc, Malvern, PA, USA). In short, the thin sections of renal tissue, once mounted on nickel grids, were first incubated with the specific antibody (1/10 dilution in phosphate buffer) for $2 \mathrm{~h}$ at room temperature; after rinsing, the sections were further incubated for $30 \mathrm{~min}$ with the protein A-gold complex. This was prepared according to techniques already described using gold particles of $14 \mathrm{~nm}$ in size [13]. Because of the nature of the antigen to be revealed (albumin), the usual pre-incubation of the sections with $1 \%$ albumin [13] was omitted. To enhance the contrast and better visualize the gold label at low magnification, most of the sections were only lightly stained with uranyl acetate. Tissues from normoglycaemic and hyperglycaemic animals were processed in parallel.

The specificity of the immunolabelling was assessed by various control experiments as described previously [13]: adsorption of the antibody by its specific antigen (rat serum albumin from Sigma Chemical Co, St.Louis, Mo, USA), use of protein A-gold alone and use of non-labelled protein A prior to the protein A-gold complex.
The density of labelling present in the mesangial regions was evaluated following the approach described previously [13]. The area occupied by basal laminae material in the mesangial region was first determined by direct planimetry. The number of gold particles on these same areas was then counted. The density was expressed as number of gold particles per $\mu^{2}$ of mesangial basal laminae material. Twenty mesangial regions were evaluated for each animal. The pictures were taken at X 4000 and enlarged to a final magnification of X 10000 . The mean value obtained for normoglycaemic animals was compared to that found for the hyperglycaemic ones using the Student's t-test.

The exact location of the gold label over the glomerular basal laminae was analyzed by a morphometrical approach. Pictures were taken at X 31000 and printed to a final magnification of X 77000. The distance between each individual gold particle and the plasma membrane at the base of the endothelial cells was recorded. Simultaneously, at the same site, the distance between the base of the endothelial cell and the podocyte was also measured. The ratio (R) between these two values was calculated. On average, 300 ratio values were recorded for each animal. The distribution of these ratio values $(0<\mathrm{R}<1)$ was determined for the normoglycaemic and hyperglycaemic animals. Mean values were calculated and both distributions were tested using the Mann-Whitney test. The Bioquant II digital image analysis system (Wild Leitz, Montral, Canada) was used for these evaluations. In a second step, the ratio values were extrapolated to the average thickness of the basal laminae found by the orthogonal intercept method, in order to evaluate the location of the gold particles through the thickness of the basal laminae $(\mathrm{R}=1=$ average thickness of the basal laminae). This was again performed for the normoglycaemic and hyperglycaemic animals.

\section{Statistical analysis}

The Student's t-test and Mann-Whitney test were performed as described above. A $p$ value of 0.001 was statistically significant.

\section{Results}

Injection of streptozotocin had induced the development of a chronic hyperglycaemic state. The injected animals studied in the present report exhibited strong glycosuria $24 \mathrm{~h}$ after the streptozotocin injection. This glycosuria remained throughout the experiment, which lasted up to 15 months.

At time of death, the body weight for the streptozotocin-injected rats averaged $300 \mathrm{~g}$ (versus over $700 \mathrm{~g}$ for the controls). Daily urine volumes in the last 5 days preceding death averaged $116 \pm 2 \mathrm{ml} / 24 \mathrm{~h}$ for the streptozotocin-injected animals (versus $6 \pm 0.6 \mathrm{ml} / 24 \mathrm{~h}$ for the controls, $p<0.0005$ ). Proteins and albumin excretion were $53.5 \pm 8.9 \mathrm{mg} / 24 \mathrm{~h}$ and $21.7 \pm 4.4 \mathrm{mg} / 24 \mathrm{~h}$ respectively (versus $24.4 \pm 3.9 \mathrm{mg} / 24 \mathrm{~h}$ and $8.8 \pm 2.9 \mathrm{mg} / 24 \mathrm{~h}$ respectively for the controls, $p<0.0005$ ). Blood glucose levels were $28.4 \pm 4.7 \mathrm{mmol} / 1$ (versus $7.1 \pm 0.7 \mathrm{mmol} / 1$ for the controls, $p<0.0005$ ) and plasma insulin levels were $24.03 \pm 2.47 \mathrm{mU} / 1$ (versus $49.20 \pm 3.89 \mathrm{mU} / 1$ for the controls, $p<0.0005$ ).

Morphological-immunofluorescence studies performed on the pancreatic tissue showed the presence of a major decrease in the number of insulin containing cells in the islets of Langerhans of the streptozotocin-injected animals when compared to those of the control animals (results not shown).

At the level of the renal glomerulus of the normoglycaemic animals, the glomerular basal laminae appeared 

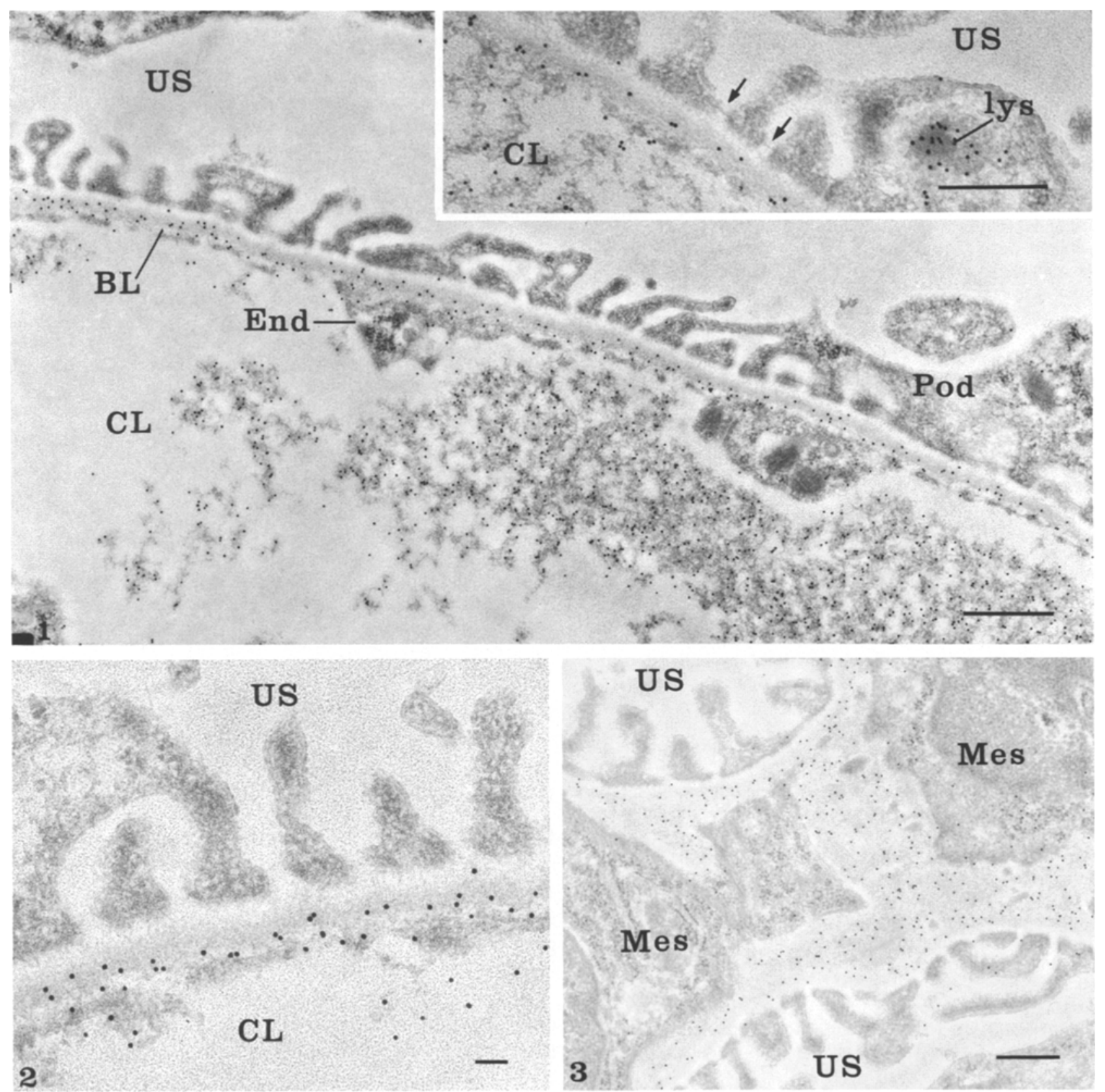

Figs. 1-3. Renal tissue from control normoglycaemic rats. Localization of rat albumin by the protein A-gold technique. The gold particles revealing albumin antigenic sites are present over the capillary lumen (CL), the endothelium (End), the glomerular basal laminae (BL) and the mesangial region. The podocytes (Pod) as well as the urinary space (US) are devoid of labelling. Over the capillary lumen, the gold particles are associated with the dense flocculent material. Over the glomerular basal laminae, most of the gold particles are associated with the basal cell membrane of the endothelial cells and with the subendothelial side of the laminae. The epithelial side of the laminae is almost free of labelling. The basal laminae around the mesangial cells (Mes) is intensely labelled. The lysosomal structure (lys) present in the podocyte is also labelled. Arrows, slit diaphragm between the foot processes of the podocytes. Figure $1 \times 28000$, bar $=0.5 \mu \mathrm{m}$; inset $\times 35000$, bar $=0.5 \mu \mathrm{m}$; Figure $2 \times 55000$, bar $=$ $0.1 \mu \mathrm{m}$; Figure $3 \times 20000$, bar $=0.5 \mu \mathrm{m}$

as a thin fibrillar layer lying between the endothelial cells of the blood capillaries and the podocytes of the epithelial cells (Fig. 1). Three different regions can be distinguished in the basal laminae: on the subendothelial side, the lamina lucida (or lamina rara) interna; in the center, the lamina densa; and on the epithelial side, the lamina lucida (or lamina rara) externa. On the other hand, the glomerular basal laminae of the streptozotocin-injected hyperglycaemic animals displayed a major increase in its thickness (Figs. 4, 6 and 7). The lamina densa seems to be the region to undergo such thickening. Evaluations on the glomerular basal laminae thickness using the orthogonal intercept method have confirmed this major modification. Indeed, the glomerular basal laminae thickness in streptozotocin-injected animals averaged $404 \pm 45 \mathrm{~nm}$ (versus $190 \pm 10 \mathrm{~nm}$ for the controls, $p<0.0005$ ).

The ultrastructural localization of rat albumin anti- 

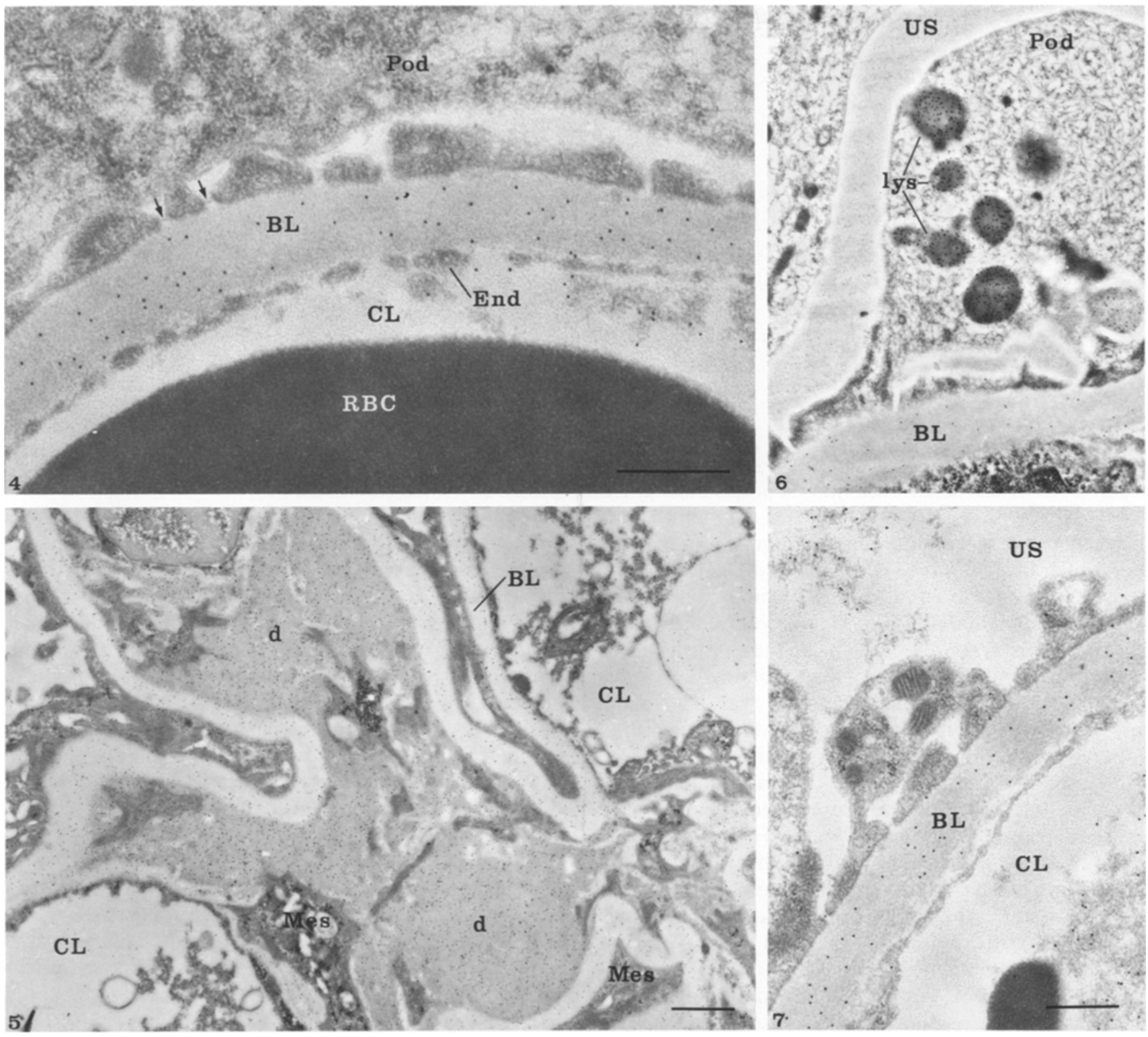

Figs. 4-7. Renal tissue from streptozotocin-induced hyperglycaemic rats. These figures demonstrate the major increase in the thickness which occurs to the glomerular basal laminae (BL) as well as the large deposits (d) of basal laminae-like material in the mesangial regions. The gold particles revealing albumin antigenic sites are present over the capillary lumen (CL) and the glomerular basal laminae (BL). No labelling is seen over the red blood cell (RBC) and the podocyte (Pod). Flocculent material present in the urinary space (US) is also labelled. Over the glomerular basal laminae the gold particles are present throughout the entire thickness. Intense labelling by gold particles is also found over the large deposits (d) among the mesangial cells (Mes). These deposits are more electron dense than the basal laminae. Numerous intensely labelled lysosomal structures (lys) are present in the podocytes. Arrows, slit diaphrams. Figure $4 \times 35000$, bar $=0.5 \mu \mathrm{m}$; Figure $5 \times 1000$, bar $=1 \mu \mathrm{m}$; Figure $6 \times 15500$, bar $=0.5 \mu \mathrm{m} ;$ Figure $7 \times 22500$, bar $=0.5 \mu \mathrm{m}$

genic sites was revealed using the protein A-gold immunocytochemical technique on glomerular tissue of normo and hyperglycaemic animals. On tissue sections of the normoglycaemic animals (Figs. 1 and 2), the gold particles were found over the lumen of the blood capillary vessels as well as over the glomerular basal laminae (Figs. 1 and 2). Labelling was absent over the urinary space (Figs. 1 and 2). Labelling over the basal laminae material in mesangial regions was intense (Fig. 3). In epithelial (podocytes) and mesangial cells, the labelling was restricted to few lysosomal structures (Fig. 1). In the lumen of the blood vessels, the labelling was particularly intense over the flocculent material which represents serum proteins maintained in the lumen by the fixation procedure. The labelling over the glomerular basal laminae appeared intense over the lamina densa, particularly on the endothelial side (Figs. 1 and 2). The lamina lucida externa, on the epithelial side, was almost free of labelling (Figs.1 and 2).

For the tissue of the streptozotocin-injected hyperglycaemic animals (Figs.4-7), the labelling, revealing albumin antigenic sites, was also found over the floccu- 


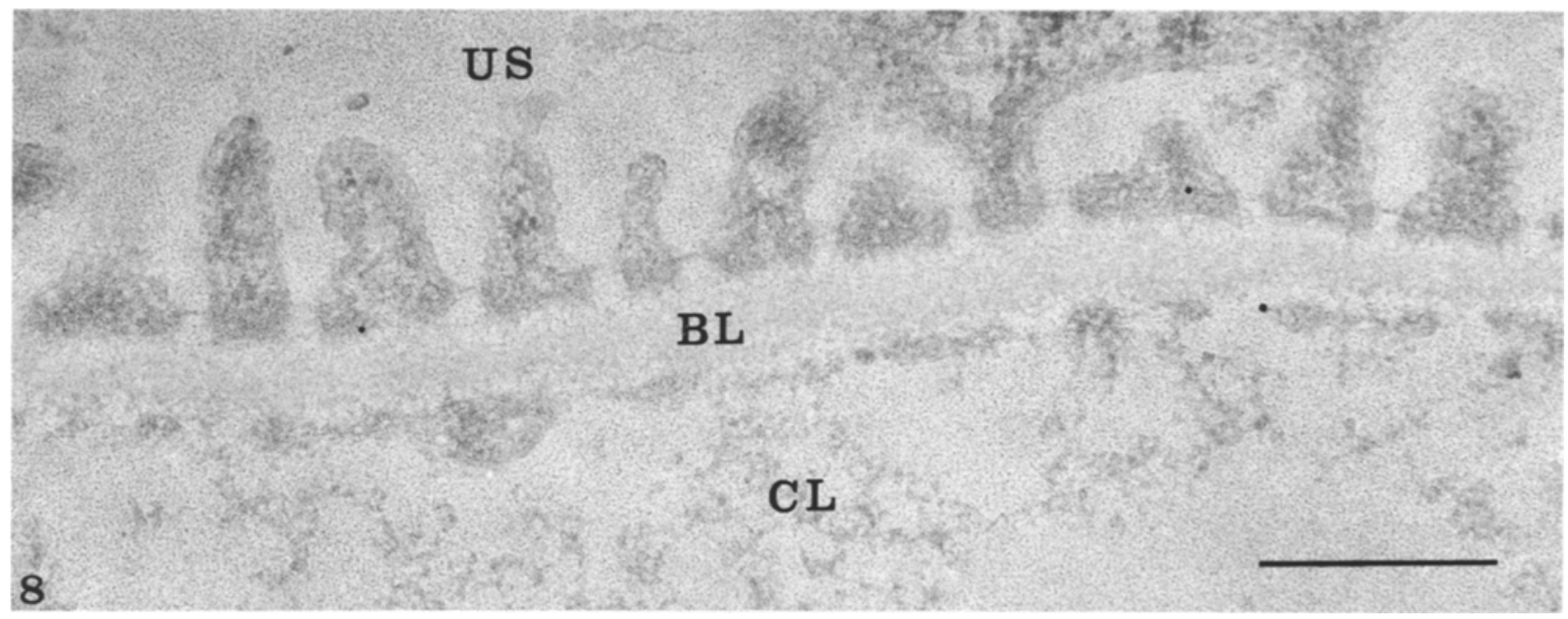

Fig. 8. Renal tissue from a normoglycaemic rat. Control of specificity. The tissue section was incubated with the anti-albumin antibody preabsorbed with rat albumin, followed by the protein A-gold complex. Very few gold particles are present over the capillary lumen (CL), the endothelial cells, the glomerular basal laminae (BL), the podocyte and the urinary space (US). $\times 50000, \mathrm{bar}=0.5 \mu \mathrm{m}$

lent material present in the capillary lumen and over the glomerular basal laminae (Figs. 4, 6 and 7). Occasionally, labelling was also found in the urinary space over some flocculent material (Fig. 7). Numerous labelled lysosomal structures were present in the epithelial cells (podocytes) (Fig.6). The labelling obtained over the thickened glomerular basal laminae was distributed throughout the entire thickness of the laminae with no apparent preferential accumulation at any site (Figs. 4, 6 and 7). In the mesangial regions, large accumulations of basal laminae material were present and they displayed intense labelling for albumin (Fig. 5). However, quantitative evaluations have demonstrated that the intensities of labelling present in mesangial regions were lower in hyperglycaemic than in normoglycaemic animals $\left(27.6 \pm 1.7\right.$ particles $/ \mu^{2}$ versus $46.4 \pm 3.3$ particles/ $\left.\mu \mathrm{m}^{2}, p<0.001\right)$.

The experiments performed in order to assess the specificity of the results have demonstrated a marked reduction in the intensities of the labelling. This result was obtained in the three conditions tested: use of the antigen-adsorbed-antibody (Fig. 8), use of protein Agold alone or the use of non-labelled protein A before applying the protein A-gold complex (not illustrated).

The differences in the distribution of the labelling over the glomerular basal laminae of normal and hyperglycaemic animals were confirmed by the morphometrical analysis; this is illustrated in Figures 9 and 10. When the distributions of the ratio values, obtained from the distance of the gold particles to the membrane of the endothelium and the thickness of the basal laminae at that same site, were compared under normal and hyperglycaemic conditions, significant differences were found (Mann-Whitney test, $p<0.001$ ). Indeed, under normal conditions, two major pics were observed, one $(\mathrm{R}<0.05)$ at the level of endothelial cell membrane and the other at $0.20<R<0.25$ (Fig. 9). The percentage of values higher than 0.65 was very low. In contrast to this, under hyperglycaemic conditions the distribution was more rectangular; the ratio values were more uniformly distributed. The pic at the level of the endothelium $(\mathrm{R}<0.05)$ remained significant. The mean values $(0.29 \pm 0.01$ and $0.42 \pm 0.01$ respectively) were significantly different $(p<0.001)$. When the distributions were reported over the average thickness of the basal laminae, the differences between both distributions were more striking (Fig. 10). Over the glomerular basal laminae of the normoglycaemic animals, a first pic of labelling was observed at the level of the endothelial cell basal plasma membrane $(<10 \mathrm{~nm})$. This was followed by a decrease at about $20 \mathrm{~nm}$ from the endothelial cells; this site corresponds to the subendothelial laminae lucida (or lamina rara interna). A second increase in the intensity of labelling was detected at about $50 \mathrm{~nm}$ from the endothelial cells; this site corresponds to the endothelial side of the lamina densa. From there, the labelling decreased to reach minimal intensities towards the epithelial cells (Fig.10). In contrast to this asymmetrical distribution, the labelling present over the glomerular basal laminae of the hyperglycaemic animals demonstrated a more or less uniform distribution throughout the thickness of the laminae from the endothelial to the epithelial sides. Only one significant pic $(<10 \mathrm{~nm})$ was observed at the level of the endothelial cell membrane (Fig. 10).

\section{Discussion}

Application of the protein A-gold technique on renal tissue has allowed for the high-resolution localization of rat serum albumin in the glomerulus and for the evaluation of its passage through the glomerular wall in normal and diabetic conditions. Renal tissue from streptozotocin-injected long-term diabetic animals was studied. In addition to reduced growth, hyperglycaemia and 

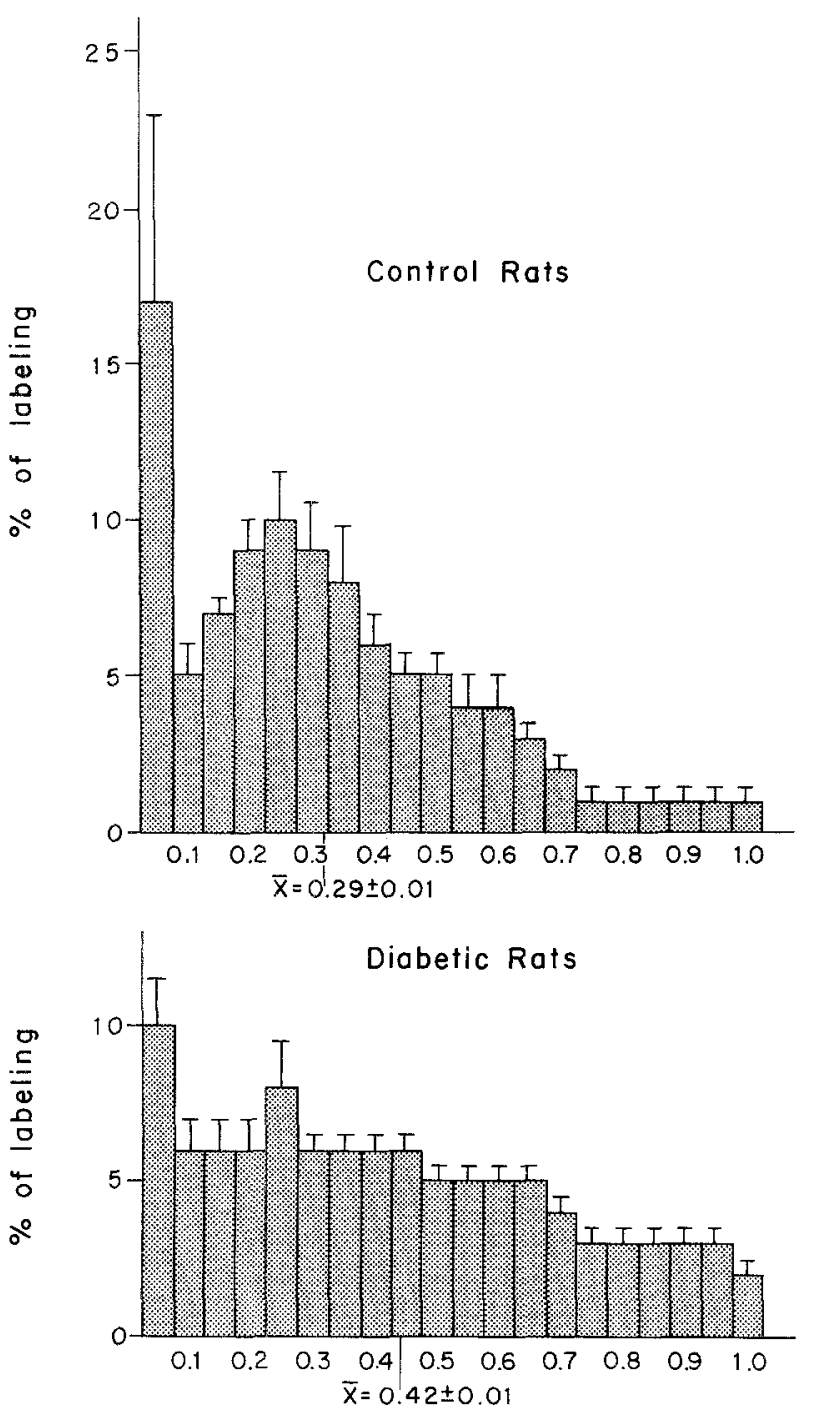

9 Ratio ( $\frac{\text { distance Endothelium-Goldporticle }}{\text { distonce Endothelium-Epithelium }}$ )

Fig.9. Distribution, as expressed over ratio values, of rat albumin immunolabelling in the glomerular basal laminae of normal and diabetic rats. The diagrams for the normal animals demonstrate the asymetrical distribution with two sites of intense labelling, one at the level of the endothelium (Fig. 10), the other in the basal laminae at about $50 \mathrm{~nm}$ from the endothelium. The diagrams for the diabetic animals demonstrate (1) the major increase in the thickness of the laminae (Fig.10) and (2) the more uniform distribution of the labelling throughout the entire thickness of the laminae

low blood insulin levels, these animals displayed the classical renal alterations of diabetic microangiopathy, with major thickening of the glomerular basal laminae, significant glycosuria, proteinuria and albuminuria. Significant differences in the distribution of albumin antigenic sites were found between normal and hyperglycaemic animals, revealing alterations in albumin glomerular permeability in diabetic condition.

Several morphological studies have investigated the filtration properties of the glomerular wall using various electron dense tracers injected in the circulation [Review, 1]. However, the approach used in these experiments is confronted with major limitations due to the non-physiological nature of the tracers and the introduction of several haemodynamic changes [15-17]. Immunocytochemistry appears to be a better approach for the study of molecular permeability, since the proteins revealed are those normally present in the tissue which are simply retained in their locations by the fixation procedure [14]. This approach was previously applied for the investigation of the glomerular permeability [21]. However, the use of the immunoperoxidase technique can lead to results of low resolution due to the massreaction product obtain through the multiple-step histochemical reactions; in addition, the reaction product can diffuse and bind to adjacent structures [22]. In contrast, the protein A-gold immunocytochemical approach yields results of much higher resolution due to the simplicity of the technique and the use of a particulate marker [14]. The fact that the labelling obtained with this approach is restricted to the surface of the sections precludes problems of penetration and diffusion of the marker. Furthermore, it allows for morphometrical and quantitative evaluations [13]. The present application of this approach on glomerular tissue of normal animals has allowed for the demonstration of albumin antigenic sites mainly at the level of the endothelial cells and the subendothelial side of the laminae densa of the glomerular wall. Very few albumin antigenic sites were detected on the epithelial side of the wall, and no evidence was found demonstrating retention of albumin by the epithelial slit diaphragm. These results suggest that two components of the glomerular wall, the endothelium and the lamina densa, play the key role in the selective glomerular permeability of serum albumin. They are in accord with the bulk of evidence obtained using various other techniques [1]. The endothelium appears to constitute the first barrier in the passage of albumin and might behave as a valve, while the lamina densa of the glomerular basal laminae represents the second filter blocking the passage of albumin to the urinary space. On the other hand, the presence of albumin immunoreactivity in lysosomal structures of the podocytes may reflect reabsorption of small amounts of albumin that normally leak through the glomerular wall $[23,24]$.

The results obtained on tissues of diabetic animals reflect a totally different situation; indeed, albumin antigenic sites were no longer preferentially accumulated at the level of the lamina densa. The distribution of the label was found to be more or less uniform throughout the entire thickness of the basal laminae. This suggests that the retention of albumin, as detected under normal conditions, is altered and that no special site in the basal lamina plays a particular role in its filtration property. Although the direct effect of streptozotocin on albumin permeability through its nephrotoxic action cannot be ruled out, the alterations observed seem to be related to the diabetic condition and are part of the microangiopathy syndrome. Indeed, these results are in agreement with the previous demonstration of albumin in the glo- 


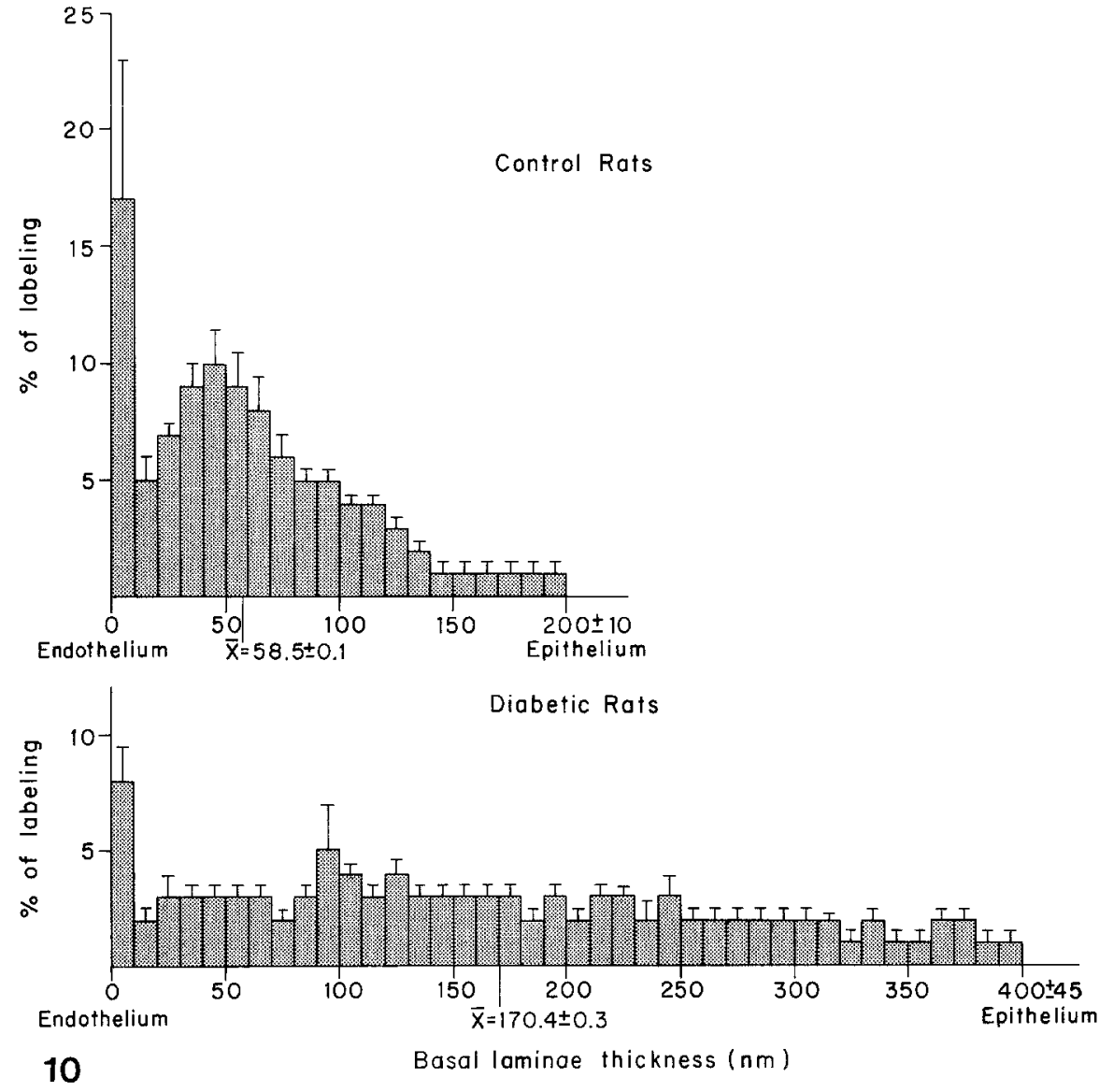

Fig. 10. Distribution, as expressed over mean values of basal laminae thickness, in the glomerular basal lamina of normal and diabetic rats. See legend to Figure 9 for further explanation merular basal lamina by both immunofluorescence [25] and biochemical techniques [26], and with the data demonstrating the presence of proteinuria and urinary albumin excretion in diabetes [review, 9]. In addition, the strong albumin immunoreactivity found in the lysosomal structures of the podocyte goes along with the hypothesis that these epithelial cells play an important role in protein reabsorption [1]. A strong reaction for albumin was also found over the basal laminae-like material present in the mesangial regions, where filtrate deposits are known to occur [1]. The fact that the intensity of albumin immunolabelling in these mesangial regions was found to be lower under hyperglycaemic conditions must be due to the large accumulation of basal laminae material observed in these regions. The rate of accumulation of material must be higher than the deposition of albumin.

The reasons for the loss of the selective filtration properties of the glomerular wall under diabetic condition is still a matter of controversy. The glomerular permeability to water and proteins is regulated by the fine interaction between various factors [27]: (a) the renal glomerular plasma flow; (b) the hydrostatic and oncotic pressure; (c) the molecular size, charge and configuration of the elements being filtered; (d) the intrinsic biochemical and biophysical properties of the glomerular capillary wall; and (e) the intraglomerular haemodynamics. Any imbalance among these factors would be expected to result in an anomalous permeability of the glomerular wall, i. e. in proteinuria [27]. Indeed, in diabetic conditions various of these factors are known to be altered. The glomerular filtration rate and the glomerular plasma flow are increased [9]. The molecular configuration of albumin is modified, since elevated levels of glycosyl-albumin are reported in diabetic subjects [28]. The biochemical and biophysical properties of the glomerular basal laminae are changed; their modifications in diabetic condition have been the subject of intense investigation. Indeed, beside the major increase in the thickness of the glomerular basal laminae [29-31], this also displays changes in its biochemical properties [32-35] and in the molecular organization of its components [18]: increased glycosylation of the collageneous constituents [32-35], decreased heparan sulfate proteoglycan component $[33,34]$ and alterations in the distribution of type IV collagen in the laminae [18]. Recently, it has been demonstrated that the heparan sulfate proteoglycan component, through its anionic charges, plays an important role in the filtration properties of the basal laminae [36]. Neutralization of the anionic charges of the proteoglycan or its removal by enzymatic treatments results in an increase in the urinary excretion of albumin [37]. Under diabetic conditions, the proteoglycans are reduced $[33,34,38-40]$. This reduction results in a net decrease in the number of anionic sites in the glomerular basal laminae which may lead to the observed passage of albumin. A combination of 
these alterations must contribute to the loss in the glomerular filtration properties.

Acknowledgements. The authors acknowledge Drs. Rasio and Letellier for their help in the biochemical evaluations of the serum and urine samples, Dr. V. Gisiger for his help in the use of the Bioquant II, and C. Venne, J.Léveillé and F. Blain for their technical assistance. This study was supported by grants from the Medical Research Council of Canada and the Canadian Diabetes Association. M. Bendayan is a Scientist of the Medical Research Council of Canada.

\section{References}

1. Farquhar MG (1975) The primary glomerular filtration barrierbasement membrane or epithelial slits? Kidney Int 8: 197-211

2. Pappenheimer JR (1953) Passage of molecules through capillary walls. Physiol Rev 33: 387-423

3. Renkin EM, Gilmore JP (1973) Glomerular filtration. In: Orloff J, Berliner RW (eds) Handbook of physiology, Vol 8. Washington, pp $185-248$

4. Ditzel J, Junker K (1973) Abnormal glomerular filtration rate, renal plasma flow and renal protein excretion in recent and shortterm diabetes. Br Med J II: 13-19

5. Mogensen CE (1971) Glomerular filtration rate and renal plasma flow in short-term juvenile diabetes mellitus. Scand J Clin Lab Invest 28: $91-100$

6. Mogensen CE, Østerby R, Gundersen HJG (1979) Early functional and morphologic vascular renal consequences of the diabetic state. Diabetologia 17:71-76

7. Mogensen CE, Andersen MJF (1973) Increased kidney size and glomerular filtration rate in early juvenile diabetes. Diabetes 22: $706-712$

8. Mogensen CE, Steffes MW, Deckert T, Christiansen JS (1981) Functional and morphological renal manifestations in diabetes mellitus. Diabetologia 21: 89-93

9. Christiansen JS, Gammelgaard J, Frandsen M, Parving H-H (1981) Increased kidney size, glomerular filtration rate and renal plasma flow in short-therm insulin-dependent diabetics. Diabetologia $20: 451-456$

10. Osterby R, Gundersen HJG (1975) Glomerular size and structure in diabetes mellitus. Early abnormalities. Diabetologia 11: $225-229$

11. Østerby R (1975) Early phases in the development of diabetic glomerulopathy. A quantitative electron microscopic study. Acta Med Scand 200 (Suppl) 574: 1-82

12. Keen $H$, Chlouverakis $C$ (1964) Urinary albumin excretion and diabetes mellitus. Lancet 2:1155-1156

13. Bendayan M (1984) Protein A-gold immunocytochemistry: technical approach, applications and limitations. J Elect Microse Tech 1: $243-270$

14. Bendayan M (1980) Use of the protein A-gold technique for the morphological study of vascular permeability. J Histochem Cytochem 28: 1251-1254

15. Cotran RS, Karnovsky MJ (1967) Vascular leakage induced by horseradish peroxidase in the rat. Proc Soc Exp Biol Med 126: $557-561$

16. Simionescu N (1979) Enzymatic tracers in the study of vascular permeability. J Histochem Cytochem 27: 1120-1130

17. Vegge $T$, Haye $R$ (1977) Vascular reactions to horseradish peroxidase in the guinea pig. Histochemistry 53:217-222

18. Bendayan $M$ (1985) Alteration in the distribution of type IV collagen in glomerular basal laminae in diabetic rats as revealed by immunocytochemistry and morphometrical approach. Diabetologia 28: $373-378$

19. Jensen EB, Gundersen HJG, Østerby R (1979) Determination of membrane thickness distribution from orthogonal intercepts. $J$ Microse 115: 19-33
20. Bendayan M, Rasio E (1981) Hyperglycemia and microangiopathy in the eel. Diabetes $30: 317-325$

21. Ryan GB, Karnovsky MJ (1976) Distribution of endogenous albumin in the rat glomerular: role of hemodynamic factors in glomerular barrier function. Kidney Int 9: 36-45

22. Courtoy PJ, Picton DH, Farquhar MG (1983) Resolution and limitations of the immunoperoxidase procedure in the localization of extracellular matrix antigens. J Histochem Cytochem 31: 945-951

23. Farquhar MG, Wissig SL, Palade GE (1961) Glomerular permeability. I. Ferritin transfer across the normal glomerular capillary wall. J Exp Med 113: 47-66

24. Caufield JP, Farquhar MG (1974) The permeability of glomerular capillaries to graded dextrans. J Cell Biol 63: 883-903

25. Westberg NG, Michael AF (1972) Immunopathology of diabetic glomerulosclerosis. Diabetes 21: 163-174

26. Michael AF, Brown DM (1981) Increased concentration of albumin in kidney basement membranes in diabetes mellitus. Diabetes 30: $843-846$

27. Kanwar JS (1984) Biophysiology of glomerular filtration and proteinuria. Lab Invest 51: 7-21

28. Dolhofer R, Wieland OH (1980) Increased glycosylation of serum albumin in diabetes mellitus. Diabetes 29: 417-422

29. Farquhar MG, Hopper JJR, Moon HD (1959) Diabetic glomerulosclerosis: electron and light microscopic studies. Am J Pathol 35: 721-753

30. Hirose K, Østerby R, Nozawa M, Gundersen HJG (1982) Development of glomerular lesions in experimental long-term diabetes in the rat. Kidney Int 21:689-695

31. Østerby R, Lundbaek K, Steen Olsen T, Orskov H (1967) Kidney lesions in rats with severe longterm alloxan diabetes. III. Glomerular ultrastructure. Lab Invest 17: 675-962

32. Beisswenger PJ, Spiro RG (1970) Human glomerular basement membrane: chemical alteration in diabetes mellitus. Science 168 596-598

33. Parthasarathy N, Spiro RG (1982) Effect of diabetes on the glycosaminoglycan component of the human glomerular basement membrane. Diabetes 31: 738-741

34. Rohrbach DH, Hassell JR, Kleinman HK, Martin GR (1982) Alterations in the basement membrane (heparan-sulfate) proteoglycan in diabetic mice. Diabetes 31: 185-188

35. Spiro RG (1976) Search for a biochemical basis of diabetic microangiopathy. Diabetologia 12:1-14

36. Kanwar YS, Linker A, Farquhar MG (1980) Increased permeability of the glomerular basement membrane to ferritin after removal of glycosaminoglycans (heparan sulfate) by enzyme digestion. $J$ Cell Biol 86: 688-693

37. Rosenzweig LJ, Kanwar YS (1982) Removal of sulfated (heparan sulfate) or non sulfated (hyaluronic acid) glycosamino-glycans results in increased permeability of the glomerular basement membrane to ${ }^{125}$ I-bovine serum albumin. Lab Invest $47: 177-184$

38. Kanwar YS, Rosenzweig LJ, Linker A, Jakubowski ML (1983) Decrease de novo synthesis of glomerular proteoglycans in diabetes: biochemical and autoradiographic evidence. Proc Natl Acad Sci USA 80: 2272-2275

39. Brown DM, Klein DJ, Michael AF, Oegama TR (1982) ${ }^{35}$ S-glycosaminoglycan and ${ }^{35} \mathrm{~S}$-glycopeptide metabolism by diabetic glomeruli and aorta. Diabetes 31:418-425

40. Cohen MP, Surma ML (1981) ${ }^{35}$ S-sulfate incorporation into glomerular basement membrane gylcosaminoglycan is decreased in experimental diabetes. J Lab Clin Med 98: 715-722

Received: 13 May 1986

and in revised form: 8 November 1986

Dr. M. Bendayan

Département d'Anatomie

Faculté de Médecine

Université de Montréal

C.P. 6128 , succursale A

Montréal (Québec)

Canada H3C 3J7 